\title{
LAG TIME STRUCTURE OF CARDIOVASCULAR DEATHS ATTRIBUTED TO AMBIENT AIR POLLUTANTS IN AHVAZ, IRAN, 2008-2015
}

\section{MARYAM DASTOORPOOR ${ }^{1}$, GHOLAMREZA GOUDARZI ${ }^{1,2}$, NARGES KHANJANI ${ }^{3}$, ESMAEIL IDANI ${ }^{1}$, HAMIDREZA AGHABABAEIAN ${ }^{4}$, and ABBAS BAHRAMPOUR ${ }^{5,6}$}

${ }^{1}$ Ahvaz Jundishapur University of Medical Sciences, Ahvaz, Iran

Air Pollution and Respiratory Diseases Research Center

${ }^{2}$ Ahvaz Jundishapur University of Medical Sciences, Ahvaz, Iran

Environmental Technologies Research Center (ETRC)

${ }^{3}$ Kerman University of Medical Sciences, Kerman, Iran

Environmental Health Engineering Research Center

${ }^{4}$ Dezful University of Medical Sciences, Dezful, Iran

Nursing and Emergency Department

${ }^{5}$ Kerman University of Medical Sciences, Kerman, Iran

Physiology Research Center

${ }^{6}$ Kerman University of Medical Sciences, Kerman, Iran

Department of Epidemiology and Biostatistics, Faculty of Public Health

\begin{abstract}
Objectives: There are few studies about the association between breathing polluted air and increased risk of cardiovascular diseases and cardiac death in the Middle East. This study has aimed to investigate the relation between air pollutants and cardiovascular mortality (based on the International Statistical Classification of Diseases and Related Health Problems, 10th revision) in Ahvaz. Material and Methods: In this ecological study, the data about cardiovascular disease mortality and air pollutants from March 2008 until March 2015 was inquired from the Ahvaz City Authority and the Khuzestan Province Environmental Protection Agency. The quasi-Poisson, second degree polynomial constrained, distributed lag model; using single and cumulative lag structures, adjusted by trend, seasonality, temperature, relative humidity, weekdays and holidays was used for the data analysis purposes. Results: Findings indicated a direct significant relation between an interquartile range (IQR) increase in ozone and cardiovascular deaths among men after 3 days' lag. There was also a significant relation between an IQR increase in particulate matter below $10 \mu \mathrm{m}$ and cardiovascular deaths for all people, over 60 years old and under 18 years old after 3 and 13 days' lags. There was a significant relation between an IQR increase in nitrogen dioxide and carbon monoxide, and cardiovascular deaths in the case of under 18-year-olds (in the lag 11) and over 60-year-olds (in the lag 9), respectively. We finally found a significant association between an IQR increase in sulfur dioxide and cardiovascular deaths in the case of men, under 18-year-olds and from 18- to 60-year-olds in the lag 9, 0, and 11, respectively (p-values < 0.05). Conclusions: It appears that air pollution is significantly associated with cardiovascular deaths in Ahvaz City. Int J Occup Med Environ Health 2018;31(4):459-473
\end{abstract}

Key words:

Air pollution, Cardiovascular diseases, Death, Mortality, Risk assessment, Iran

Funding: This study was supported by Kerman University of Medical Sciences (Ethic Committee No. 17090) (grant No. 94/595 entitled "The association between air pollutants in Ahwaz city with cardiovascular, and respiratory mortality and traffic accidents," project manager: Narges Khanjani, Ph.D.).

Received: August 22, 2016. Accepted: September 25, 2017.

Corresponding author: Narges Khanjani, Environmental Health Engineering Research Center, Kerman University of Medical Sciences, Haft Bagh Alavi Highway, 76169-13555 Kerman, Iran (e-mail: n_khanjani@kmu.ac.ir). 


\section{INTRODUCTION}

Human health is vastly influenced by environmental and climatic conditions. Nowadays, various natural and artificial sources have caused changes in the physical and chemical properties of ambient air and have caused "air pollution" [1,2]. Air pollutants have a wide range of impacts on human health and are considered to be one of the major environmental health issues in mega-industrial world cities [3].

This problem has exacerbated with population growth, urban development, increased motor vehicles and expansion of urban traffic, rapid economic development, inappropriate use of systems and industrial devices, increased energy consumption and non-compliance with environmental regulations $[4,5]$. The effect of air pollution on disease and morbidity has been suggested for a long time now. Even before conducting modern epidemiological studies in this field, events such as the sharp increase in particulate matter in England (London, 1952) which led to a sharp increase in the number of deaths during a short time, had attracted attention [6].

The World Health Organization estimates that air pollution is responsible for more than 1 million premature deaths each year across the world [7]. Recent studies conducted in relation to air pollution have shown that not only Western Europe and North America but also developing countries are facing this health problem [8-11]. And it is possible that there is a relationship between chronic exposure to air pollution and coronary artery diseases [12]. A study from the US has shown that air pollution may be associated with increased cardiovascular disease especially morbidity and mortality from coronary heart disease; and exposure to particulate matter (PM) is associated with myocardial infarction and stroke [13]. There was also a positive relation between particulate matter below $10 \mu \mathrm{m}\left(\mathrm{PM}_{10}\right)$ and death from coronary heart disease in the ecological study done by Maheswaran et al. in Sheffield, England [14]. The results of Cesaroni et al.'s study in Rome showed that there was a strong correlation between particulate matter below $2.5 \mu \mathrm{m}\left(\mathrm{PM}_{2.5}\right)$ and nitrogen dioxide $\left(\mathrm{NO}_{2}\right)$ with cardiovascular deaths and deaths from ischemic heart diseases, after adjusting for confounding factors [15].

The results of Dadbakhsh et al. in Shiraz, Iran also showed that nitrogen monoxide (NO) and nitrogen oxides $\left(\mathrm{NO}_{\mathrm{X}}\right)$ were significantly related to total cardiovascular deaths; $\mathrm{NO}, \mathrm{NO}_{\mathrm{x}}$ and sulfur dioxide $\left(\mathrm{SO}_{2}\right)$ were significantly related to female deaths and $\mathrm{SO}_{2}$ was significantly related to deaths in the case of 18 - to 60-yearolds. Nitrogen monoxide and $\mathrm{NO}_{\mathrm{x}}$ pollutants were also related to all cardiovascular deaths that happened one month later [2].

The most important adverse effects of air pollution include the incidence of cardiovascular complications such as heartthrob, fluctuating heart rate, increased blood pressure, increased vascular tone, blood coagulation, atherosclerosis [16] and increased mortality [17]. Studies have shown that patients with congestive heart disease [18] and a history of myocardial infarction [19] are at a higher risk of deaths on days with higher concentrations of air pollution; and the effects of long-term exposure to air pollution are probably stronger for deaths with cardiovascular and respiratory causes than other causes of death [13]. Industrial development and increase in the number of motor vehicles have increased atmospheric pollutants all over the world, and therefore conducting studies from various parts of the world may help provide a better understanding of the global problem of air pollution [20].

Several studies have been conducted about the effect of air pollution on cardiovascular deaths with cross-sectional, cohort and time series methodologies [2,15,21,22]. However, a study that evaluates the acute effect of air pollution on cardiovascular deaths has not been conducted in Ahvaz yet; and so far the only available knowledge has been obtained through studies carried out using the Air Q model to estimate the effects of air pollution on respiratory and cardiovascular diseases [22-24]. In this study, the 
relation between aggregated daily counts of cardiovascular deaths with the average daily levels of ambient air pollutants in the period of 7 years has been evaluated. In this study, researchers have focused on the probable acute effects of air pollution, which happened on the same day or up to 14 days later.

Ahvaz, the capital of Khuzestan province, is Iran's second largest city in terms of area after Tehran and Iran's fifthlargest city in terms of population. Air pollution in this city has increased in the recent years and has become more severe [25]. Based on the World Health Organization's report in 2013, Ahvaz was the most polluted city in regard to $\mathrm{PM}_{10}$ in the world [26].

\section{MATERIAL AND METHODS}

\section{Area of study}

Ahvaz city has an area of $530 \mathrm{~km} 2$. It is the capital city of Khuzestan province, and is located at $31^{\circ} 20^{\prime} \mathrm{N}$ and $48^{\circ} 40^{\prime} \mathrm{E}$. According to the 2011 census, Ahvaz resides 286032 households and 1.11 million people [27].

\section{Data gathering}

This ecological study has been based on the recorded data from March 2008 until March 2015 from Ahvaz, Iran. The daily data about mortalities from cardiovascular diseases was obtained from the Deputy of Health at the Ahvaz Jundishapur University, classified according to age and gender.

In this study, all cardiovascular deaths according to the definition of the International Classification of Diseases and Related Health Problems, 10th revision (ICD-10), which were I00-I78 and included diseases of heart (ICD-10 codes: I00-I09, I11, I13, I20-I51); essential hypertension and hypertensive renal disease (I10, I12, I15) and cerebrovascular diseases (I60-I69) were enrolled [28]. The ambient air pollution data was inquired from the Khuzestan Province Environmental Protection Agency for 7 major pollutants, which included ozone $\left(\mathrm{O}_{3}\right)$, parti- culate matter below $10 \mu \mathrm{m}\left(\mathrm{PM}_{10}\right)$, nitrogen dioxide $\left(\mathrm{NO}_{2}\right)$, carbon monoxide $(\mathrm{CO})$ and sulfur dioxide $\left(\mathrm{SO}_{2}\right)$.

Particulate matter below $10 \mu \mathrm{m}$ was the only type of particulate matter, which had been recorded at the air quality monitoring stations. There were 4 air quality monitoring stations in Ahvaz, including the environmental protection agency station (Mohit Zist), Naderi square station, University square station (Behdasht Ghadim), and the meteorological organization station (Havashenasi) [8]. According to the environmental protection agency experts, the air quality monitoring station locations were representative of the ambient air quality of the whole city.

Air quality monitoring stations are environmentally classified into urban, suburban, traffic, background, industrial, and rural stations. The stations in Ahvaz are urban type stations, which include the built-up urban area with the exception of city parks, the built-up area that is not mixed with non-urbanized areas. For measuring ozone, the urban area is defined as locations such as residential and commercial areas of cities, parks (away from the trees), big streets or squares with very little or no traffic, open areas used for educational, sports or recreation purposes. Urban sites measure air quality which is representative of a few square kilometers around them.

In Ahwaz, air pollutants were measured hourly in these stations; and, we calculated the daily mean of air pollutants, by using moving averages.

The data on mean, maximum and minimum temperature, average relative humidity, number of sunny days, total evaporation, total rainfall and wind speed was inquired from the meteorological organization of Khuzestan province.

There is just one synoptic station in Ahvaz, so meteorological parameters were collected from the Ahvaz meteorological station. This station is located at 48 $74^{\prime}$ E, 3134' N [8]. Parameters measured and reported at this station include air pollutants concentrations, rainfall, sunshine, evaporation, air temperature, dew point and relative humidity, air pressure, wind speed and visibility, and wind direction. 
The daily cardiovascular diseases mortality data was matched with the daily averages of air pollutants and weather data.

\section{Statistical analysis}

In order to estimate missing data, the expectation maximum (EM) method was used. This method is an expansion of the regression methods, in which, by using the available data, regression models are built and are used for estimating missing values. In this method, the parameters of regression are continuously estimated and are then updated by using the new parameters. This method is repeated several times until the difference between 2 consecutive regression coefficients becomes less than $10^{-6}[29]$.

Descriptive statistics including frequency, median, mean, standard deviation, maximum and minimum were used for summarizing data about cardiovascular deaths, ambient air pollutants and weather.

Air pollution might be associated with mortality happening on the same day or a few days later. In this case, lag structures should be applied. However, we can't use multiple lags in one model, as the collinearity between these parameters is high [27]. In order to deal with this problem, distributed lag models (DLM) with smoothing functions have been used [28]. In studies DLMs have been used for quantifying the cumulative effect of pollutants over multiple-lagged days [27,29].

In the study, the association between cardiovascular mortalities with mean daily air pollution was analyzed using the quasi-Poisson, second degree polynomial constrained, distributed lag model; using single and cumulative lag structures, adjusted by trend, seasonality, temperature, relative humidity, weekdays and holidays. Single-day lag effects of air pollutant exposure were estimated for lags from 1 to 14 days. Distributed lag models with lags of 0-14 days were also used for estimating cardiovascular mortalities with potential cumulative exposure effects.
We calculated lags only up to 14 day as we were looking for the more acute effects of air pollution on cardiovascular mortalities.

Analyses were performed using $\mathrm{R}$ software, v. 3.2.5. The level of significance in this study was considered below 0.05 .

\section{RESULTS}

Descriptive statistics of pollutants, meteorological parameters and cardiovascular deaths

The number of cardiovascular deaths that happened in various subgroups in the period March 2008 - March 2015 in Ahvaz is shown in the Table 1. The total number of cardiovascular deaths was 10625.

Cardiovascular disease mortality in all, men and women, and over 60-year-olds showed a significant increase as compared to 2013 (Figure 1).

Due to the middle eastern dust (MED) storms in Ahvaz, $\mathrm{PM}_{10}$ was the major air pollutant with varying values for each season. The average value of this pollutant was

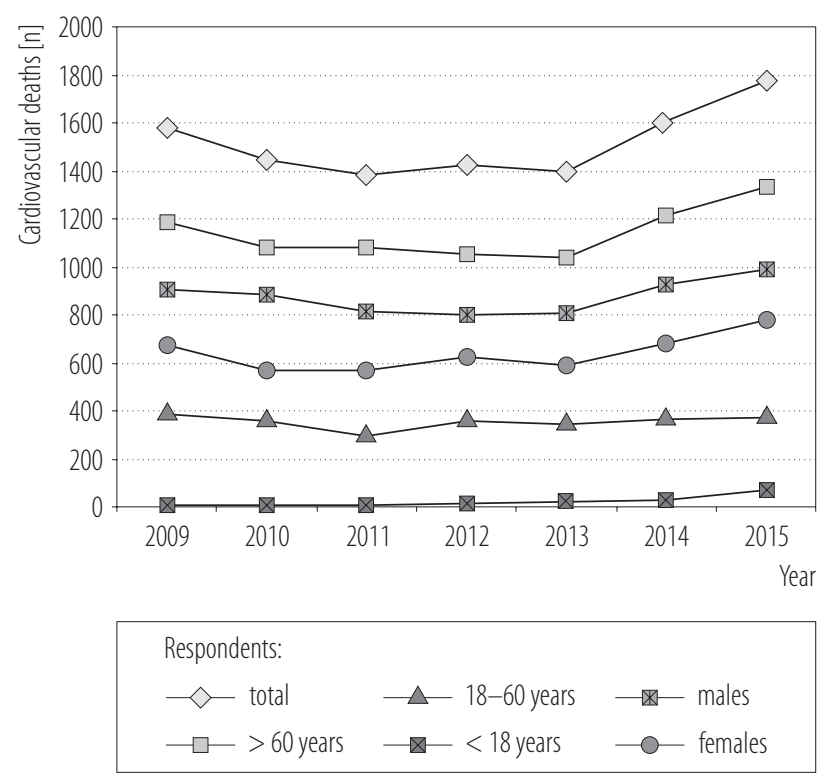

Fig. 1. Cardiovascular disease mortality in Ahvaz, Iran, March 2009 - March 2015 
Table 1. Cardiovascular deaths in Ahvaz City, Iran, March 2008 - March 2015, breakdown by sex and age

\begin{tabular}{lc}
\hline Characteristics & $\begin{array}{c}\text { Cardiovascular deaths } \\
(\mathrm{N}=10625) \\
{[\mathrm{n}]}\end{array}$ \\
\hline Sex & \\
male & 6139 \\
female & 4486 \\
Age & \\
$<$ 18 years & 163 \\
18-60 years & 2476 \\
$>60$ years & 7986 \\
\hline
\end{tabular}

above $200 \mu \mathrm{g} / \mathrm{m}^{3}$ on most days in the years under consideration (Table 2).

A summary of air pollution and climatic data for the years under consideration has been shown in the Table 3 .

\section{Single and cumulative lag structure analysis}

The relation between cardiovascular deaths in the total population, females, males and various age groups and air pollutants in the single lag and cumulative lags has been shown in the Table 4 and 5 and Figure 2.

In the model adjusted for trend, seasonality, temperature, relative humidity, weekdays and holidays, among

Table 2. Frequency of particulate matter below $10 \mu \mathrm{m}\left(\mathrm{PM}_{10}\right)$ in Ahvaz City, Iran, March 2008 - March 2015

\begin{tabular}{|c|c|c|}
\hline Air quality index (AQI) & Air pollution level & $\begin{array}{c}\text { Frequency of } \mathrm{PM}_{10} \\
{[\%]}\end{array}$ \\
\hline $0-50 \mu \mathrm{g} / \mathrm{m}^{3}$ & good & 1.8 \\
\hline $51-100 \mu \mathrm{g} / \mathrm{m}^{3}$ & satisfactory & 40.8 \\
\hline $101-200 \mu \mathrm{g} / \mathrm{m}^{3}$ & moderately polluted & 45.0 \\
\hline $201-300 \mu \mathrm{g} / \mathrm{m}^{3}$ & poor & 3.6 \\
\hline $301-400 \mu \mathrm{g} / \mathrm{m}^{3}$ & very poor & 2.1 \\
\hline $401-500 \mu \mathrm{g} / \mathrm{m}^{3}$ & severe & 1.7 \\
\hline$>500 \mu \mathrm{g} / \mathrm{m}^{3}$ & more than the defined range by the US EPA [30] & 5.1 \\
\hline$>100 \mu \mathrm{g} / \mathrm{m}^{3}$ & above the threshold & 57.5 \\
\hline
\end{tabular}

US EPA - United States Environmental Protection Agency.

Table 3. Descriptive indices of air pollutants reported as per day and climate factors in Ahvaz, Iran, March 2008 - March 2015

\begin{tabular}{lrccc}
\hline \multicolumn{1}{c}{ Variable } & $\mathrm{M}$ & $\mathrm{Me}$ & \multicolumn{1}{c}{ Min.-max } & $\mathrm{SD}$ \\
\hline $\mathrm{O}_{3}\left[\mu \mathrm{g} / \mathrm{m}^{3}\right]$ & 62.000 & 47.200 & $5.700-6509.200$ & 206.000 \\
$\mathrm{PM}_{10}\left[\mu \mathrm{g} / \mathrm{m}^{3}\right]$ & 237.200 & 162.500 & $25.000-4498.000$ & 289.800 \\
$\mathrm{NO}_{2}\left[\mu \mathrm{g} / \mathrm{m}^{3}\right]$ & 44.200 & 39.600 & $0.300-427.100$ & 34.200 \\
$\mathrm{CO}\left[\mu \mathrm{g} / \mathrm{m}^{3}\right]$ & 1.300 & 0.900 & $0.010-21.900$ & 2.000 \\
$\mathrm{SO}_{2}\left[\mu \mathrm{g} / \mathrm{m}^{3}\right]$ & 54.900 & 43.800 & $2.500-614.300$ & 48.200 \\
Temperature (total) $\left[{ }^{\circ} \mathrm{C}\right]$ & 26.700 & 27.100 & $11.600-39.500$ & 9.100 \\
$\quad$ min. & 19.700 & 20.000 & $18.800-20.400$ & 0.600 \\
$\quad$ max & 33.600 & 33.900 & $32.600-34.300$ & 0.600 \\
Relative humidity $[\%]$ & 43.100 & 41.000 & $19.000-77.000$ & 15.800 \\
\hline
\end{tabular}


Table 3. Descriptive indices of air pollutants reported as per day and climate factors in Ahvaz, Iran, March 2008 - March 2015 - cont.

\begin{tabular}{lrrrr}
\hline \multicolumn{1}{c}{ Variable } & M & Me & \multicolumn{1}{c}{ Min.-max } & \multicolumn{1}{c}{ SD } \\
\hline Total rainfall $[\mathrm{mm}]$ & 14.000 & 2.400 & $0.000-113.000$ & 23.400 \\
Total sunshine $[\mathrm{h}]$ & 256.400 & 253.200 & $144.000-374.000$ & 62.600 \\
Total evaporation $[\mathrm{mm}]$ & 264.700 & 255.200 & $41.000-541.000$ & 161.300 \\
Wind speed $[\mathrm{m} / \mathrm{s}]$ & 11.500 & 10.000 & $7.000-44.000$ & 5.300 \\
\hline
\end{tabular}

$\mathrm{O}_{3}$ - ozone; $\mathrm{PM}_{10}$ - particulate matter below $10 \mu \mathrm{m} ; \mathrm{NO}_{2}$ - nitrogen dioxide; $\mathrm{CO}$ - carbon monoxide; $\mathrm{SO}_{2}$ - sulfur dioxide.

$\mathrm{M}$ - mean; Me - median; min. - minimal value; max - maximal value; SD - standard deviation.
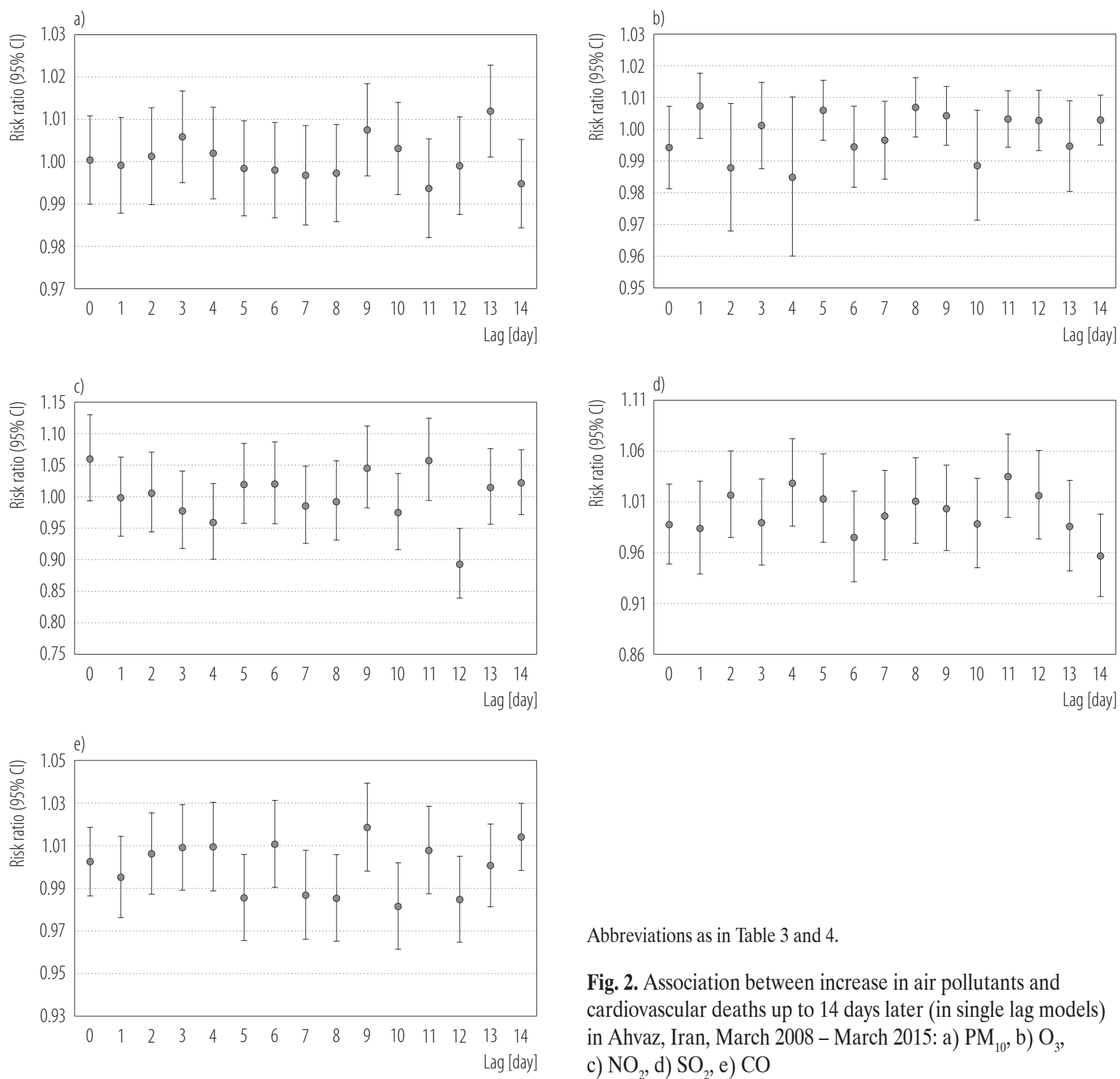

Abbreviations as in Table 3 and 4.

Fig. 2. Association between increase in air pollutants and cardiovascular deaths up to 14 days later (in single lag models) in Ahvaz, Iran, March 2008 - March 2015: a) $\mathrm{PM}_{10}$, b) $\mathrm{O}_{3}$, c) $\mathrm{NO}_{2}$, d) $\mathrm{SO}_{2}$, e) $\mathrm{CO}$ 


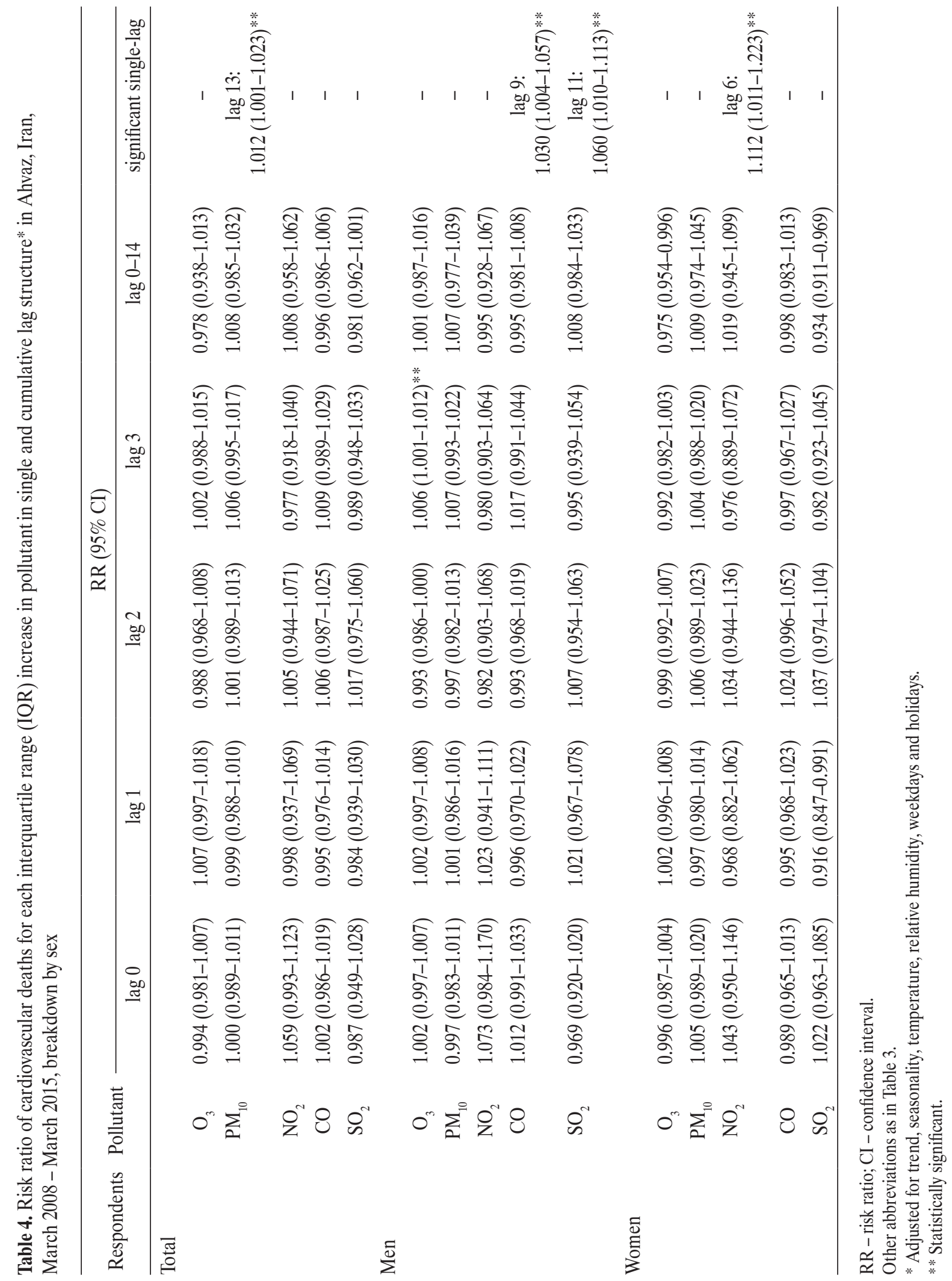




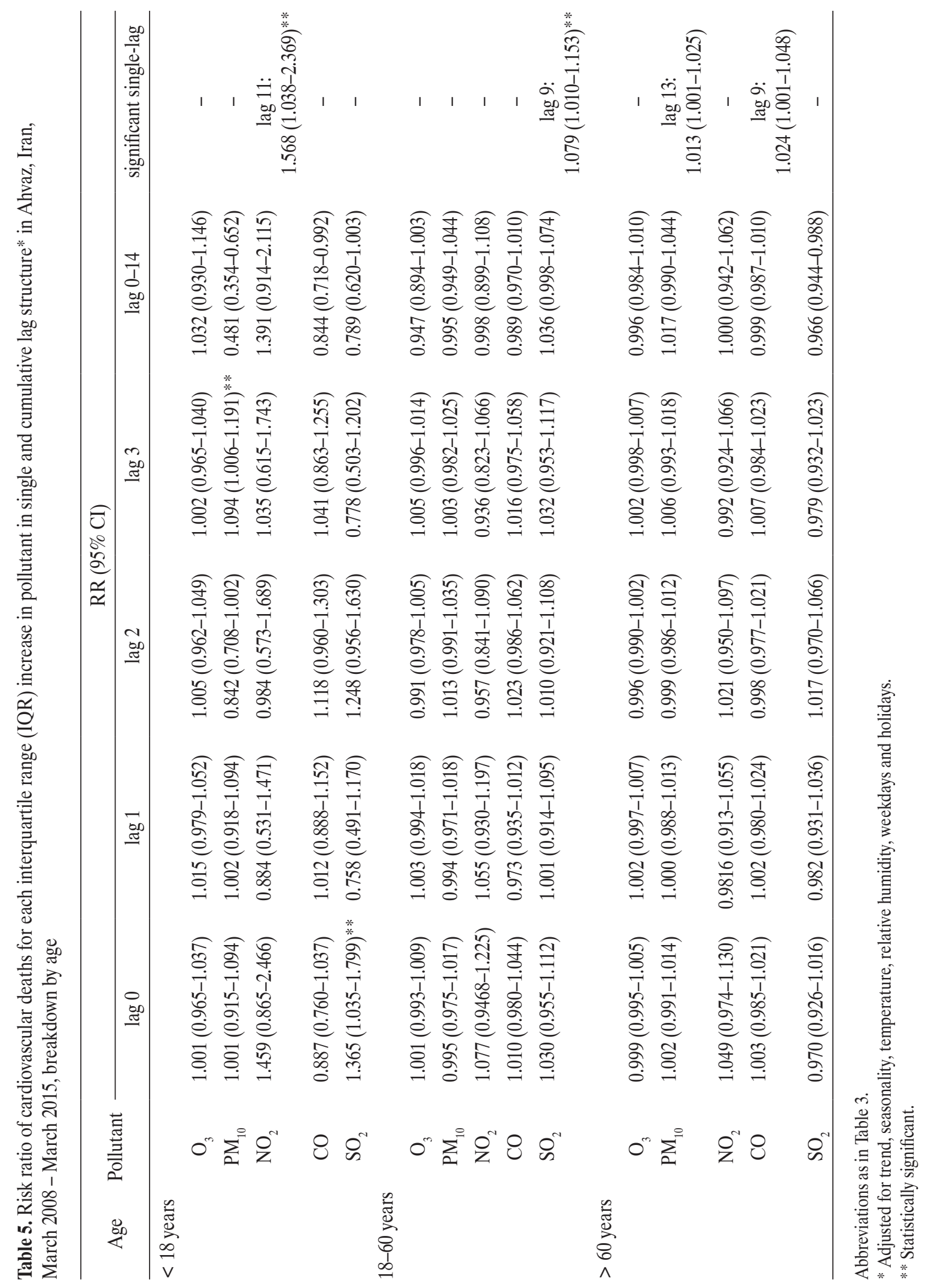


males, after 3 days' lag for the IQR increase in the mean of the $\mathrm{O}_{3}$ pollutant (which was about $72.7 \mu \mathrm{g} / \mathrm{m}^{3}$ ), the risk ratio (RR) for cardiovascular deaths was 1.006 (95\% confidence interval (CI): 1.001-1.012) and significant.

For $\mathrm{PM}_{10}$ in the total population and in the case of 60-year-olds in the adjusted model after 13-day lags and for the IQR increase in the average of $\mathrm{PM}_{10}$ (which was $237.3 \mu \mathrm{g} / \mathrm{m}^{3}$ ), the rate ratio for cardiovascular deaths increased 1.012 (95\% CI: 1.001-1.023) and 1.013 (95\% CI: 1.001-1.025), respectively. The results also showed that in the case of under 18-year-olds, $\mathrm{PM}_{10}$ in 3 days' lags was related to increased cardiovascular deaths $\mathrm{RR}=1.094$ (95\% CI: 1.006-1.191).

For $\mathrm{NO}_{2}$ the only significant relation was in the case of under 18-year-olds and 11 days after exposure, in which for the IQR (about $61.3 \mu \mathrm{g} / \mathrm{m}^{3}$ ) increase, the $\mathrm{RR}=1.568$ (95\% CI: $1.038-2.369$ ) was reported.

Results showed that for the IQR increase in CO (about $1.12 \mu \mathrm{g} / \mathrm{m}^{3}$ ), the adjusted RR for cardiovascular deaths with 9-day lags in the population above 60 years old was significant RR = 1.024 (95\% CI: 1.001-1.048).

The adjusted models also showed that in the lag of 11, 0 , and 9 days after exposure for the IQR increase in the mean concentration of $\mathrm{SO}_{2}$ (about $62.2 \mu \mathrm{g} / \mathrm{m}^{3}$ ), the RR in the case of males, under 18-year-olds and from 18- to 60-year-olds was 1.06 (95\% CI: 1.01-1.113), 1.365 (95\% CI: 1.035-1.799) and 1.079 (95\% CI:1.01-1.153), respectively (Table 3, 4 and Figure 2).

\section{DISCUSSION}

Air pollution may affect cardiovascular health by causing endothelial dysfunction, vasoconstriction, atherosclerosis, coagulation changes, inflammatory and oxidative stress responses, autonomic imbalance, increased blood pressure and arrhythmias [12]. The adverse effects of air pollution on cardiovascular health have been shown in some observational epidemiological studies. However, there are a few studies about the acute effect of air pollution on cardiovascular deaths in the Middle East, especially Iran. Therefore, this study has aimed to investigate the relation between air pollutants in Ahvaz and cardiovascular deaths. The time unit in this study has been days and we have been looking for the acute effects of air pollution. In this study, we have only evaluated the effects of air pollution up to 14 days after exposure.

This study has shown a positive and significant relationship between the concentrations of ambient air $\mathrm{O}_{3}$ (ground level ozone) and cardiovascular deaths among males after 3 days' lags. The relation between cardiac admission and $\mathrm{O}_{3}$ during the warm months was investigated in various previous studies. But, the results were inconsistent with positive and significant estimates in London [30] and negative and significant estimates in Hong Kong [31].

In the study conducted by Hashemi and Khanjani in Kerman, Iran, the adjusted results showed that $\mathrm{O}_{3}$ had a positive and significant correlation with cardiovascular admission in the total population and among women [21]. But in another study by the same researchers, the adjusted analysis did not show a positive and significant relationship between ambient air $\mathrm{O}_{3}$ and cardiovascular deaths [32]. In the study by Jerrett et al. in America, there was no significant relation between $\mathrm{O}_{3}$ and cardiovascular or total deaths. However, relatively weak positive associations were seen between ambient air $\mathrm{O}_{3}$ and cardiovascular mortality when adjusted for $\mathrm{PM}_{2.5}$ [33]. Some other studies did not show a significant effect of $\mathrm{O}_{3}$ on cardiac deaths, either. For example, there was no relationship between $\mathrm{O}_{3}$ and cardiac deaths in the studies from Dockery et al. in England and Pope et al. in America [34,35]. In the study done by Lipsett et al. in California, the relation between ischemic heart disease (IHD) death and $\mathrm{O}_{3}$ was barely significant (hazard ratio $(\mathrm{HR})=1.06,95 \%$ CI: $0.99-1.06)$, but when the analysis was limited to summer, $\mathrm{O}_{3}$ was positively and significantly correlated with deaths from IHD (HR $=1.09$, 95\% CI: 1.01-1.19). 
Meanwhile, there was no relation between $\mathrm{O}_{3}$ and cardiovascular mortality [36]. Chuang et al. in a cross-sectional study on 1023 elderly people in Taiwan reported that systolic and diastolic blood pressure had a strong, significant and positive correlation with the annual average level of $\mathrm{O}_{3}$ [37]. But the study from Norway found no association between $\mathrm{O}_{3}$ and blood pressure [38] and even a significant negative correlation was observed for $\mathrm{O}_{3}$ in a multicenter study about the effects of air pollution on blood pressure in the Netherlands, Finland and Germany [39]. In another study from Panama, there was no statistically significant relationship between cardiovascular deaths and $\mathrm{O}_{3}$ after one or 2 months' lags in any age group [40]. In Hong Kong, the results showed no significant positive correlation between total cardiovascular deaths and $\mathrm{O}_{3}$ pollution at the same time ( $\mathrm{RR}=0.997,95 \% \mathrm{CI}$ : 0.99-1.003) but there was a positive and significant correlation between deaths due to ischemic heart disease and $\mathrm{O}_{3}$ after 3-day lags ( $\mathrm{RR}=1.009,95 \%$ CI: $1.001-1.018)$ [41]. It seems that the controversial results about ozone's health effects require more investigations.

Results of this study also showed that $\mathrm{PM}_{10}$ was directly and significantly associated with mortality from cardiovascular diseases for all people, over 60 -year-olds and under 18-year-olds, after 3 and 13 days' lag time. In the study conducted on 30 cities in a number of European countries, positive correlations were reported between cardiovascular deaths and $\mathrm{PM}_{10}$ after up to 40 days' delay. Cardiovascular mortality increased up to $1.97 \%$ (95\% CI: 1.38-2.55) in 40-day-lagged models and most of the effects of air pollution remained for more than a month after exposure to this air pollutant. In fact, when the effects after 40 days' delay were assessed, the effect of $\mathrm{PM}_{10}$ on cardiovascular deaths increased to double and these effects were also seen in age subgroups. These increased effects are important for risk assessment and show that the effects of air pollution in regard to cardiovascular death exist even after one month or longer after exposure [42]. In another study from Panama, results showed the effect of $\mathrm{PM}_{10}$ on cardiovascular deaths in total increases by 5.8\% (95\% CI: 1.99.7) after one month's delay [40].

However, in another study conducted by Braga et al., in 10 US cities, results showed that cardiovascular deaths in contrary to respiratory deaths, which were affected by the level of $\mathrm{PM}_{10} 2$ days before (time lag 2), were affected by the level of $\mathrm{PM}_{10}$ on the same day as well [43]. In the study performed in the city of São Paulo about the effect of $\mathrm{PM}_{10}$ on cardiovascular disease admissions, after 20 days' delay, a different pattern was observed for cardiovascular diseases in the total population, women and men. In the total population the effect was positive and significant in zero and one-day lags, negative and significant (harvesting) - in 4- to 6-day lags and again positive and significant - in 10- to 12-day lags [44]. In a systematic review study conducted by Shah et al. in 2012, the results showed that the relation between hospitalizations and deaths from heart failure and levels of $\mathrm{PM}_{10}$ on the same day was RR $=1.63,95 \%$ CI: $1.2-2.07$ ) but not significant after 1- or 2-month delays [45].

In this study, there was a positive and strong significant relationship between $\mathrm{NO}_{2}$ and cardiovascular deaths in the case of under 18-year-olds after 11-day lags. In this regard, in Dadbakhsh et al.'s study, in Shiraz, Iran, the results showed that $\mathrm{NO}$ and $\mathrm{NO}_{\mathrm{x}}$ had a direct and significant relation with total cardiovascular deaths, and female deaths in the same month and total cardiovascular deaths that happened one month later [2]. In the study from China, nitrogen dioxide was also associated with an increase in ischemic heart disease death [41]. The study done by Ghozikali et al. in Tabriz, Iran, showed that $\mathrm{NO}_{2}$ concentration over $10 \mu \mathrm{g} / \mathrm{m}^{3}$ was related to $0.47 \%$ (95\% CI: $0-0.94$ ) increase in cardiovascular mortality in Tabriz [46]. In the study done by Cesaroni et al. in Rome, although there was no or poor relation between $\mathrm{NO}_{2}$ and non-accidental deaths, cardiovascular deaths and death from ischemic heart diseases in the crude analysis; there was a strong re- 
lation between $\mathrm{NO}_{2}$ and these deaths when adjusted for personal characteristics and socio-economic status based on the residential area [15].

In the study about the relation between air pollution and mortality in France, the adjusted multivariate analysis showed that the hazard ratio for cardiovascular death for each $10 \mu \mathrm{g} / \mathrm{m}^{3}$ increase in $\mathrm{NO}_{2}$ was 1.27 (95\% CI: 1.041.56), which was statistically significant [47]. In the multicenter cohort study in Europe, using Poisson regression analysis of 22006 survivors of a first myocardial infarction, the RR of readmission due to heart attack in relation to $\mathrm{NO}_{2}$ was 1.032 (95\% CI: $1.013-1.051$ ) for each $8 \mu \mathrm{g} / \mathrm{m}^{3}$ (i.e., $4.16 \mathrm{ppb}$ ) increase and it was concluded that there was an increased risk for heart attack during days with increasing concentrations of several urban air pollutants, including $\mathrm{PM}_{10}, \mathrm{CO}, \mathrm{NO}_{2}$, and $\mathrm{O}_{3}$ [48].

In another cohort study in Toronto, Canada, there was a significant increase of $17 \%$ in all-cause mortality and $40 \%$ increase in cardiovascular mortality for each $4 \mathrm{ppb}$ increase in $\mathrm{NO}_{2}$ after controlling for age, gender, lung function, obesity, smoking and neighborhood deprivation [49]. In the study done by Raaschou-Nielsen et al. in Denmark, the adjusted mortality rate ratio (MRR) for cardiovascular diseases was 1.26 (95\% CI: 1.06-1.51). In other words, there was a significant $26 \%$ increase in cardiac death when the concentrations of $\mathrm{NO}_{2}$ doubled [50]. Zeng et al. conducted a study in 6 cities of China, and showed that after one day's lag time, for each $10 \mu \mathrm{g} / \mathrm{m}^{3}$ increase in $\mathrm{NO}_{2}$, cardiovascular deaths increased up to $1.03 \%$ (95\% CI: $0.4-$ 1.66) [51]. In the study conducted by Zúñiga et al. in Panama, the results showed that after one month's lag, $\mathrm{NO}_{2}$ with concentrations $\geq 20 \mu \mathrm{g} / \mathrm{m}^{3}$ increased cardiovascular deaths for age groups above 85 years old by $6.7 \%$ (95\% CI: 0.9-12.8) [40]. In another study carried out by Wong et al. in Hong Kong, the results showed that there was a positive and significant correlation between ischemic heart disease deaths and $\mathrm{NO}_{2}$ after 1-day de- lay $(\mathrm{RR}=1.024,95 \%$ CI: 1.012-1.036) [41]. A systematic review done by Mustafić in 2012 based on 34 studies finally showed that $\mathrm{NO}_{2}$ had a significant positive relation with myocardial infarction $(\mathrm{HR}=1.011$, 95\% CI: 1.006-1.016) [52].

In this study, there was a statistically significant relation between $\mathrm{CO}$ and cardiovascular deaths in the case of over 60-year-olds in 9-day lags. However, a systematic review conducted by Shah et al. in 2012, showed that the RR between the number of hospitalizations and deaths of heart failure and $\mathrm{CO}$ on the same day (zero time lag) was $\mathrm{RR}=3.52$ (95\% CI: 2.52-4.54) but was not significant in delayed lags [45].

In this study there was a statistically significant relation between simultaneous $\mathrm{SO}_{2}$ and cardiovascular deaths among men, the < 18 and 18-60-year-olds in lag times 9, 0 and 11, respectively. In this regard, Zeng et al. showed that $\mathrm{SO}_{2}$ per $10 \mu \mathrm{g} / \mathrm{m}^{3}$ increase after one-day delay increased cardiovascular deaths by $0.48 \%$ (95\% CI: $0.11-$ 0.85) [51]. In the study conducted by Martins et al. in São Paulo City, Southeastern Brazil, the results showed that there was a positive and significant relation between $\mathrm{SO}_{2}$ after zero and one-day lags with admission for IHD and all cardiovascular diseases in the case of the total population and female patients [44]. In the study from Hong Kong, there was a positive and significant correlation between deaths due to ischemic heart disease and $\mathrm{SO}_{2}$ after 1-day lag ( $\mathrm{RR}=1.028,95 \%$ CI: 1.012-1.044) as well [41]. Investigating the effects of air pollution and cause-specific mortality (cardiovascular, respiratory, etc.) after delays may help discover the relation between pollutants and causes of death and provide more insight for finding the mechanisms of effects of ambient air pollutants on those deaths [43]. Some of the mechanisms for the effect of air pollutants on cardiovascular outcomes have been mentioned in studies. Of course, it is difficult to estimate the effects of each individual air pollutant separately in epidemiological studies [50]. It has been reported that exposure to air pollution 
is associated with increased blood viscosity and shortening of prothrombin time in human populations [53]. Animal studies have also shown that prolonged exposure to particles causes atherosclerosis [44] and probably does the same in the case of humans [36].

Some studies have suggested that $\mathrm{NO}_{2}$ itself causes thrombosis [54]. But others have suggested that the known vasodilation effects of $\mathrm{NO}$ and $\mathrm{PM}_{10}$ are highly variable and may have varied physiological effects, depending on the dominant combination [55].

The strength of our study has arisen from the use of a big database that had collected population data over a long time period.

The limitations of this study have included the aggregated data, and the fact that the inference cannot be directly transferred to the individual level. Population-based ecological studies cannot take care of population dynamics, for example, immigrations and emigrations, either. In this study, exposure to air pollution has been measured for the population as a whole and not at an individual level. However, this has been the only way we could measure exposure in this particular population. Although we have finally studied temporal variability, we have not been able to account for the probable difference in exposure based on location.

\section{CONCLUSIONS}

The results indicate that cardiovascular death is associated with air pollution $\left(\mathrm{O}_{3}, \mathrm{PM}_{10}, \mathrm{NO}_{2}, \mathrm{CO}\right.$ and $\left.\mathrm{SO}_{2}\right)$ on the same day and in multi-day lags in Ahvaz City. This finding shows the need for effective planning to reduce the harmful effects of air pollution on human health.

\section{ACKNOWLEDGMENTS}

The authors thank the Deputy of Health at Jundishapur University of Medical Sciences, the Khoozestan Province Environmental Protection Agency and the Ahwaz City Bureau of Meteorology.

\section{REFERENCES}

1. Mansouri F, Khanjani N, Pourmousa R. Forecasting ambient air pollutants by time series models in Kerman, Iran. J School Public Health Inst Public Health Res. 2013;11(2):75-86.

2. Dadbakhsh M, Khanjani N, Bahrampour A. Death from cardiovascular diseases and air pollution in Shiraz, Iran (March 2006-March 2012). J Epidemiol Prev Med. 2016;2(1):114-6, https://doi.org/10.19104/jepm.2016.114.

3. Qian Z, He Q, Lin H-M, Kong L, Liao D, Dan J, et al. Association of daily cause-specific mortality with ambient particle air pollution in Wuhan, China. Environ Res. 2007; 105(3):380-9, https://doi.org/10.1016/j.envres.2007.05.007.

4. Dastoorpoor M, Idani E, Khanjani N, Goudarzi G, Bahrampour A. Relationship between air pollution, weather, traffic, and traffic-related mortality. Trauma Mon. 2016; 21(4):e37585, https://doi.org/10.5812/traumamon.37585.

5. Vahedian M, Khanjani N, Mirzaee M, Koolivand A. Ambient air pollution and daily hospital admissions for cardiovascular diseases in Arak, Iran. ARYA Atheroscler. 2017;13(3): $117-34$.

6. Davidson JE, Powers K, Hedayat KM, Tieszen M, Kon AA, Shepard E, et al. Clinical practice guidelines for support of the family in the patient-centered intensive care unit: American College of Critical Care Medicine Task Force 2004-2005. Crit Care Med. 2007;35(2):605-22, https://doi.org/10.1097/01. CCM.0000254067.14607.EB.

7. Anenberg SC, Schwartz J, Shindell D, Amann M, Faluvegi G, Klimont Z, et al. Global air quality and health co-benefits of mitigating near-term climate change through methane and black carbon emission controls. Environ Health Perspect. 2012;120(6):831-9, https://doi.org/10.1289/ehp.1104301.

8. Dastoorpoor M, Idani E, Goudarzi G, Khanjani N. Acute effects of air pollution on spontaneous abortion, premature delivery, and stillbirth in Ahvaz, Iran: a time-series study. Environ Sci Pollut Res Int. 2017;1-12, https://doi.org/10.1007/ s11356-017-1034-7.

9. Kesavachandran C, Pangtey B, Bihari V, Fareed M, Pathak M, Srivastava A, et al. Particulate matter concentration 
in ambient air and its effects on lung functions among residents in the National Capital Region, India. Environ Monit Assess. 2013;185(2):1265-72, https://doi.org/10.1007/s10661012-2630-0.

10. Vahedian M, Khanjani N, Mirzaee M, Koolivand A. Associations of short-term exposure to air pollution with respiratory hospital admissions in Arak, Iran. J Environ Health Sci Eng. 2017;15(1):17, https://doi.org/10.1186/s40201-017-0277-z.

11. Khanjani N, Ranadeh-Kalankesh L, Mansouri F. Air pollution and respiratory deaths in Kerman, Iran (from 2006 till 2010). Iran J Epidemiol. 2012;8(3):58-65.

12. Brook RD, Rajagopalan S, Pope CA, Brook JR, Bhatnagar A, Diez-Roux AV, et al. Particulate matter air pollution and cardiovascular disease. An update to the scientific statement from the American Heart Association. Circulation. 2010;121(21):2331-78, https://doi.org/10.1161/ CIR.0b013e3181dbece1.

13. Crouse DL, Peters PA, van Donkelaar A, Goldberg MS, Villeneuve PJ, Brion O, et al. Risk of nonaccidental and cardiovascular mortality in relation to long-term exposure to low concentrations of fine particulate matter: A Canadian national-level cohort study. Environ Health Perspect. 2012;120(5):708-14, https://doi.org/10.1289/ehp.1104049.

14. Maheswaran R, Haining RP, Brindley P, Law J, Pearson T, Fryers PR, et al. Outdoor air pollution, mortality, and hospital admissions from coronary heart disease in Sheffield, UK: A small-area level ecological study. Europ Heart J. 2005;26(23):2543-9, https://doi.org/10.1093/eurheartj/ehi457.

15. Cesaroni G, Badaloni C, Gariazzo C, Stafoggia M, Sozzi R, Davoli M, et al. Long-term exposure to urban air pollution and mortality in a cohort of more than a million adults in Rome. Environ Health Perspect. 2013;121(3):324-8, https:// doi.org/10.1289/ehp.1205862.

16. Simkhovich BZ, Kleinman MT, Kloner RA. Air pollution and cardiovascular injury: Epidemiology, toxicology, and mechanisms. J Am Coll Cardiol. 2008;52(9):719-26, https:// doi.org/10.1016/j.jacc.2008.05.029.
17. Goldberg MS, Burnett RT, Bailar JC, Brook J, Bonvalot Y, Tamblyn $\mathrm{R}$, et al. The association between daily mortality and ambient air particle pollution in Montreal, Quebec: 1. Nonaccidental mortality. Environ Res. 2001;86(1):12-25, https://doi.org/10.1006/enrs.2001.4242.

18. Kwon H-J, Cho S-H, Nyberg F, Pershagen G. Effects of ambient air pollution on daily mortality in a cohort of patients with congestive heart failure. Epidemiology. 2001;12(4): 413-9, https://doi.org/10.1097/00001648-200107000-00011.

19. Bateson TF, Schwartz J. Who is sensitive to the effects of particulate air pollution on mortality?: A case-crossover analysis of effect modifiers. Epidemiology. 2004;15(2):143-9, https://doi.org/10.1097/01.ede.0000112210.68754.fa.

20. Saldiva PH, Lichtenfels A, Paiva P, Barone I, Martins M, Massad E, et al. Association between air pollution and mortality due to respiratory diseases in children in São Paulo, Brazil: A preliminary report. Environ Res. 1994;65(2):218-25, https://doi.org/10.1006/enrs.1994.1033

21. Hashemi Y, Khanjani N. Air pollution and cardiovascular hospital admissions in Kerman, Iran. J Heart Cardiol. 2016;2(2):1-6, https://doi.org/10.15436/2378-6914.16.018.

22. Yari AR, Goudarzi G, Geravandi S, Dobaradaran S, Yousefi F, Idani E, et al. Study of ground-level ozone and its health risk assessment in residents in Ahvaz City, Iran during 2013. Toxin Rev. 2016;35(3-4):201-6, https://doi.org/10.1080/1556 9543.2016.1225769.

23. Goudarzi G, Geravandi S, Idani E, Hosseini SA, Baneshi MM, Yari AR, et al. An evaluation of hospital admission respiratory disease attributed to sulphur dioxide ambient concentration in Ahvaz from 2011 through 2013. Environ Sci Pollut Res Int. 2016;23(21):22001-7, https://doi.org/10.1007/s11356-016-7447-x.

24. Dobaradaran S, Geravandi S, Goudarzi G, Idani E, Salmanzadeh S, Soltani F, et al. Determination of cardiovascular and respiratory diseases caused by PM10 exposure in Bushehr, 2013. J Mazandaran Univ Med Sci. 2016;26(139):42-52.

25. Idani E, Dastoorpoor M, Goudarzi G, Khanjani N. Severe outbreaks of respiratory syndromes following autumn rainfall in Khuzestan, Iran. Arch Iran Med. 2016;19(12):884-5. 
26. Tabatabaei SA, Treur J. Comparative analysis of the efficiency of air source heat pumps in different climatic areas of Iran. Procedia Environ Sci. 2016;34:547-58, https://doi. org/10.1016/j.proenv.2016.04.048.

27. Maleki H, Sorooshian A, Goudarzi G, Nikfal A, Baneshi MM. Temporal profile of $\mathrm{PM}_{10}$ and associated health effects in one of the most polluted cities of the world (Ahvaz, Iran) between 2009 and 2014. Aeolian Res. 2016;22:135-40, https://doi.org/10.1016/j.aeolia.2016.08.006.

28. World Health Organization. International Statistical Classification of Diseases and Related Health Problems. Geneva: The Organization; 2004.

29. Dempster AP, Laird NM, Rubin DB. Maximum likelihood from incomplete data via the EM algorithm. J Royal Stat Soci B. 1977;39(1):1-38.

30. Mintz D. Guidelines for the Reporting of Daily Air Quality - Air Quality Index (AQI). EPA-454/B-06-001. Research Triangle Park (NC): U.S. Environmental Protection; 2006.

31. Wong C-M, Atkinson RW, Anderson HR, Hedley AJ, Ma S, Chau PY-K, et al. A tale of 2 cities: Effects of air pollution on hospital admissions in Hong Kong and London compared. Environ Health Perspect. 2002;110(1):67-77, https:// doi.org/10.1289/ehp.0211067.

32. Hashemi S, Khanjani N, Soltaninejad Y, Momenzadeh R. Air pollution and cardiovascular mortality in Kerman from 2006 to 2011. Am J Cardiovasc Dis Res. 2014;2(2):27-30.

33. Jerrett M, Burnett RT, Pope III CA, Ito K, Thurston G, Krewski D, et al. Long-term ozone exposure and mortality. New Engl J Med. 2009;360(11):1085-95, https://doi.org/ 10.1056/NEJMoa0803894.

34. Pope III CA, Burnett RT, Thun MJ, Calle EE, Krewski D, Ito $\mathrm{K}$, et al. Lung cancer, cardiopulmonary mortality, and long-term exposure to fine particulate air pollution. JAMA. 2002;287(9):1132-41, https://doi.org/10.1001/jama.287.9.1132.

35. Dockery DW, Pope CA, Xu X, Spengler JD, Ware JH, Fay ME, et al. An association between air pollution and mortality in 6 US cities. New Engl J Med. 1993;329(24):1753-9, https://doi.org/10.1056/NEJM199312093292401.
36. Lipsett MJ, Ostro BD, Reynolds P, Goldberg D, Hertz A, Jerrett $\mathrm{M}$, et al. Long-term exposure to air pollution and cardiorespiratory disease in the California teachers study cohort. Am J Respir Crit Care Med. 2011;184(7):828-35, https://doi.org/10.1164/rccm.201012-2082OC.

37. Chuang K-J, Yan Y-H, Chiu S-Y, Cheng T-J. Long-term air pollution exposure and risk factors for cardiovascular diseases among the elderly in Taiwan. Occup Environ Med. 2011;68(1):64-8, https://doi.org/10.1136/oem.2009.052704.

38. Madsen C, Nafstad P. Associations between environmental exposure and blood pressure among participants in the Oslo Health Study (HUBRO). Eur J Epidemiol. 2006;21(7): 485-91, https://doi.org/10.1007/s10654-006-9025-x.

39. Ibald-Mulli A, Timonen KL, Peters A, Heinrich J, Wolke G, Lanki T, et al. Effects of particulate air pollution on blood pressure and heart rate in subjects with cardiovascular disease: A multicenter approach. Environ Health Perspect. 2004 Mar;112(3):369-77, https://doi.org/10.1289/ ehp.6523.

40. Zúñiga J, Tarajia M, Herrera V, Urriola W, Gómez B, Motta J. Assessment of the possible association of air pollutants $\mathrm{PM}_{10}, \mathrm{O}_{3}, \mathrm{NO}_{2}$ with an increase in cardiovascular, respiratory, and diabetes mortality in Panama City: A 2003 to 2013 data analysis. Medicine. 2016;95(2):1-8, https://doi. org/10.1097/MD.0000000000002464.

41. Wong T, Tam W, Yu T, Wong A. Associations between daily mortalities from respiratory and cardiovascular diseases and air pollution in Hong Kong, China. Occup Environ Med. 2002;59(1):30-5, https://doi.org/10.1136/oem.59.1.30.

42. Zanobetti A, Schwartz J, Samoli E, Gryparis A, Touloumi G, Peacock J, et al. The temporal pattern of respiratory and heart disease mortality in response to air pollution. Environ Health Perspect. 2003;111(9):1188.

43. Braga ALF, Zanobetti A, Schwartz J. The lag structure between particulate air pollution and respiratory and cardiovascular deaths in 10 US cities. J Occup Environ Med. 2001;43(11):927-33, https://doi.org/10.1097/00043764-20011 1000-00001. 
44. Martins LC, Pereira LA, Lin CA, Santos UP, Prioli G, Carmo Luiz O, et al. The effects of air pollution on cardiovascular diseases: Lag structures. Rev Saude Publica. 2006;40(4): 677-83, https://doi.org/10.1590/S0034-89102006000500018.

45. Shah AS, Langrish JP, Nair H, McAllister DA, Hunter AL, Donaldson K, et al. Global association of air pollution and heart failure: A systematic review and meta-analysis. Lancet. 2013;382(9897):1039-48, https://doi.org/10.1016/S01406736(13)60898-3.

46. Ghozikali MG, Borgini A, Tittarelli A, Amrane A, Naddafi K, Mohammadyan M, et al. Quantification of the health effects of exposure to air pollution (NO2) in Tabriz, Iran. Fresen Environ Bull. 2015;24(11C):4142-8.

47. Filleul L, Rondeau V, Vandentorren S, Le Moual N, Cantagrel A, Annesi-Maesano I, et al. Twenty five year mortality and air pollution: Results from the French PAARC survey. Occup Environ Med. 2005;62(7):453-60, https://doi. org/10.1136/oem.2004.014746.

48. Von Klot S, Peters A, Aalto P, Bellander T, Berglind N, D'Ippoliti D, et al. Ambient air pollution is associated with increased risk of hospital cardiac readmissions of myocardial infarction survivors in 5 European cities. Circulation. 2005;112(20):3073-9, https://doi.org/10.1161/CIRCULATIONAHA.105.548743.

49. Jerrett M, Finkelstein MM, Brook JR, Arain MA, Kanaroglou P, Stieb DM, et al. A cohort study of traffic-related air pollution and mortality in Toronto, Ontario, Canada.
Environ Health Perspect. 2009;117(5):772-7, https://doi. org/10.1289/ehp.11533.

50. Raaschou-Nielsen O, Andersen ZJ, Hvidberg M, Jensen SS, Ketzel M, Sørensen M, et al. Air pollution from traffic and cancer incidence: A Danish cohort study. Environ Health. 2011;10(1):1-11, https://doi.org/10.1186/1476-069X-10-67.

51. Zeng Q, Li G, Zhang L, Tian L, Pan X. [Acute effects of $\mathrm{SO}_{2}$ and $\mathrm{NO}_{2}$ on mortality in the 6 cities of China]. Zhonghua Yu Fang Yi Xue Za Zhi. 2015;49(12):1085-91. Chinese.

52. Mustafić H, Jabre P, Caussin C, Murad MH, Escolano S, Tafflet M, et al. Main air pollutants and myocardial infarction: A systematic review and meta-analysis. JAMA. 2012;307(7):713-21, https://doi.org/10.1001/jama.2012.126.

53. Baccarelli A, Zanobetti A, Martinelli I, Grillo P, Hou L, Giacomini S, et al. Effects of exposure to air pollution on blood coagulation. J Thromb Haemost. 2007;5(2):252-60, https://doi.org/10.1111/j.1538-7836.2007.02300.x.

54. Maheswaran R, Pearson T, Smeeton NC, Beevers SD, Campbell MJ, Wolfe CD. Outdoor air pollution and incidence of ischemic and hemorrhagic stroke: A small-area level ecological study. Stroke. 2012;43(1):22-7, https://doi. org/10.1161/STROKEAHA.110.610238.

55. Sørensen M, Hoffmann B, Hvidberg M, Ketzel M, Jensen SS, Andersen ZJ, et al. Long-term exposure to traffic-related air pollution associated with blood pressure and self-reported hypertension in a Danish cohort. Environ Health Perspect. 2012;120(3):418-24, https://doi.org/10.1289/ehp.1103631.

This work is available in Open Access model and licensed under a Creative Commons Attribution-NonCommercial 3.0 Poland License - http://creativecommons.org/ licenses/by-nc/3.0/pl/deed.en. 